\title{
PROTECTION OF HAMSTERS AGAINST CLOSTRIDIUM DIFFICILE ILEOCAECITIS BY PRIOR COLONISATION WITH NON-PATHOGENIC STRAINS
}

\author{
S. P. Borriello and Fiona E. Barclay \\ Division of Communicable Diseases, Clinical Research Centre, Watford Road, Harrow, \\ Middlesex $H A 13 U J$
}

\begin{abstract}
Summary. Prior colonisation of clindamycin-treated hamsters with non-toxigenic strains of $C$. difficile protected them from subsequent colonisation with a toxigenic pathogenic strain. In total, 13 of 18 'protected' hamsters survived for up to 27 days whereas all 27 animals challenged with the toxigenic strain alone died within $48 \mathrm{~h}$. Protection was not evident if a heat-killed suspension was used or if the colonising non-toxigenic strain was first removed with vancomycin. No antitoxic activity could be detected in the faeces of animals colonised with the non-toxigenic strains. Other species of clostridia did not protect against the lethal effects of subsequent exposure to the toxigenic strain. Conversely, non-toxigenic strains would not protect the animals from the lethal effects of a different clostridial pathogen, $C$. spiroforme. In most cases, even in the protected animals, the toxigenic strain eventually became dominant and caused disease, with translocation across the gut wall occurring early in the disease process. It was also shown that a non-toxigenic strain of $C$. difficile can adhere to gut mucosa. It is proposed that the protection afforded by the non-toxigenic strains may be due to competition for ecological niches.
\end{abstract}

\section{INTRODUCTION}

The Syrian hamster model has contributed significantly to the elucidation of the aetiology of antibiotic-associated diarrhoea and colitis (Bartlett et al., 1978a; Chang et $a l ., 1978$ ) and has yielded important information on aspects of pathogenicity (Price $e t$ al., 1979), epidemiology (Larson et al., 1980) and treatment (Bartlett et al., 1977; Browne et al., 1977; Bartlett et al., 1978b). Disease in these animals is induced by the administration of antibiotics and subsequent exposure to pathogenic $C$. difficile, neither alone being sufficient to produce disease if the animals are housed in protected (i.e., C. difficile-free) environments (Larson et al., 1980). Disease in hamsters is due to disruption of the normal gut flora which allows $C$. difficile to colonise and produce toxins. The importance of the normal gut flora in protection against colonisation with C. difficile is suggested by the work of Wilson et al. (1981) who showed that colitis can be prevented in antibiotic-treated hamsters by the administration of homogenates of 
normal hamster caecal flora. Similar approaches to the restoration of faecal homoeostasis have been used successfully in man as a form of treatment for $C$. difficile infection (Bowden et al., 1981; Schwan et al., 1983). Many attempts have been made to identify the individual antagonistic components of the faecal flora (Rolfe et al., 1981; Barclay and Borriello, 1982 and 1984; Malamou-Ladas and Tabaqchali, 1982) and there has been recent interest in the possible antagonism between toxigenic and non-toxigenic strains of $C$. difficile (Borriello et al., 1982 and 1983; Wilson and Sheagren, 1983; Borriello and Barclay, 1984). In these studies, it was independently shown that prior colonisation of antibiotic-treated hamsters protected the animals against subsequent colonisation with a toxigenic strain. However, these studies were limited. The aims of the present study were to confirm our initial observations and those of Wilson and Sheagren (1983), to extend this model to study the specificity of the protection, and to investigate possible mechanisms of protection.

\section{MATERIAL AND METHODS}

Sources of bacteria. The strains of $C$. difficile were isolated in this laboratory from faeces. The pathogenic toxigenic strain B-1 was isolated from a patient with pseudomembranous colitis. The non-pathogenic, non-toxigenic strains used were M-1 isolated from an adult with Shigella sonnei diarrhoea and two strains, S-1 and D-1, isolated from dogs in a previous study (Borriello et al., 1983). The strains of $C$. sporogenes, $C$. perfringens, $C$. beijerincki $(C$. beijerinckii) and $C$. bifermentans were isolated in this laboratory from the stools of healthy subjects. The toxigenic strain of C. spiroforme was isolated from a rabbit with antibiotic-associated iota-enterotoxaemia (Borriello and Carman, 1983).

Identification of isolates. All strains of $C$. difficile used for inoculation and those isolated during the experiments were identified by their ability to grow on selective agar medium (Willey and Bartlett, 1979; Borriello and Honour, 1981); the characteristic fluorescence of their colonies under long-wave ultraviolet light (George et al., 1979; Borriello and Honour, 1981); colonial and cellular morphology on non-selective medium (Borriello and Honour, 1981); their characteristic volatile fatty acid products of metabolism after growth in chopped-meat-carbohydrate (CMC) broth (Holdeman et al., 1977); and their carbohydrate-fermentation reaction profiles (Holdeman et al., 1977). The strains of $C$. sporogenes, $C$. perfringens, $C$. beijerincki and $C$. bifermentans were identified according to the criteria of Holdeman et al. (1977), and the toxigenic strain of $C$. spiroforme was as described by Borriello and Carman (1983).

Toxin detection. Cytotoxin in caecal or pellet emulsions was detected by filtering a ten-fold dilution of the emulsion and applying the filtrate to a monolayer of human fibroblast cells (MRC 5; Borriello, 1978). Cell-free filtrates derived from 48-h anaerobic cultures of $C$. difficile in CMC broth (Southern Group Laboratories, Hither Green, London) were similarly tested for the presence of cytotoxin. In both cases, any cytopathic effect observed was neutralised with $C$. sordelli antitoxin (Wellcome Research Laboratories, Beckenham, Kent). In the experiments in which $C$. spiroforme was the pathogen, neutralisation tests were performed with the cross-reacting anti- $C$. perfringens type $\mathrm{E}$ iota toxin (Wellcome Research Laboratories). In addition, the non-toxigenic strains used in the experiments were shown to be non-lethal to mice after intraperitoneal (i.p.) injection of cell-free filtrates, as described by Banno et al. (1981). Strain M-1 was confirmed as non-enterotoxigenic (D. M. Lyerly, personal communication) and strain B-1 as enterotoxigenic (J. Ketley, personal communication), by an ELISA technique (Lyerly et al., 1983). As the cytotoxigenic $C$. difficile strain B-1 was shown also to be enterotoxigenic by the ELISA technique and lethal to mice on i.p. injection of cell-free filtrates, this strain will be referred to as toxigenic. Conversely, as enterotoxin production could not be demonstrated in the non-cytotoxigenic $C$. difficile strain M-1 by ELISA or mouse lethality tests, and as the non-cytotoxigenic $C$. difficile strains $S-1$ and D-1 were also negative in the mouse lethality test, indicating lack of enterotoxin production (Banno et al., 1981), these strains will be referred to as non-toxigenic.

Incubation conditions. Anaerobic incubation was at $37^{\circ} \mathrm{C}$ in an atmosphere of $\mathrm{CO}_{2} 10 \%, \mathrm{H}_{2}$ 
$10 \%$ and $\mathrm{N}_{2} 80 \%$ in an anaerobic incubator housed in an anaerobic cabinet (Forma Scientific, Marietta, Ohio, USA).

Preparation of inoculum. Suspensions of $C$. difficile were prepared by inoculating $0 \cdot 5-\mathrm{ml}$ volumes of a young stock Robertson's cooked meat culture into 10-ml volumes of pre-reduced Brain Heart Infusion Broth (Difco Laboratories, West Molesey, Surrey, England) containing L-cysteine $\mathrm{HCl} 0.05 \% \mathrm{w} / \mathrm{v}$ and sodium formaldehyde sulphoxylate $0.03 \%$ as reducing agents (BHI broth) and incubating anaerobically for $18 \mathrm{~h}$. Five $\mathrm{ml}$ of this culture were inoculated into $100 \mathrm{ml}$ of BHI broth which was similarly incubated for $18 \mathrm{~h}$, and then centrifuged at $4500 \mathrm{rpm}$ at $4{ }^{\circ} \mathrm{C}$ for $15 \mathrm{~min}$; the pellet was washed twice by re-suspending in $100-\mathrm{ml}$ volumes of fresh $\mathrm{BHI}$ broth. The pellet was finally suspended in $10 \mathrm{ml}$ of fresh BHI broth and this provided the inoculum for the animal experiments. The suspension of the toxigenic strain B-1 invariably contained $10^{8}$ organisms $/ \mathrm{ml}$ and suspensions of the non-toxigenic strains $\mathrm{M}-1, \mathrm{~S}-1$ and D-1 contained $10^{8}, 10^{10}$ and $10^{7} \mathrm{C}$. difficile $/ \mathrm{ml}$ respectively. The concentrations of other clostridial suspensions used in these experiments were as follows: $C$. sporogenes $10^{9} / \mathrm{ml}, C$. bifermentans $10^{7} / \mathrm{ml}, C$. perfringens $10^{8} / \mathrm{ml}, C$. beijerincki $10^{6} / \mathrm{ml}$, and C. spiroforme $10^{3} / \mathrm{ml}$.

Isolation of bacteria. Pellets and caecal contents for culture were prepared as $10 \%$ emulsions in glycerol transport broth (Crowther, 1977). Three serial tenfold dilutions were made in BHI broth and $0 \cdot 1-\mathrm{ml}$ portions seeded on to a selective medium (Borriello and Honour, 1981) incorporating sodium taurocholate $0.1 \% \mathrm{w} / \mathrm{v}$ (Raibaud et al., 1980; Wilson, et al., 1982) for the isolation of $C$. difficile; alcohol-treated dilutions were seeded on to BHI blood agar (Borriello et al., 1978) for the isolation of other clostridia (Koransky et al., 1978) as well as C. difficile (Borriello and Honour, 1981). All the media were incubated anaerobically for $48 \mathrm{~h}$ at $37^{\circ} \mathrm{C}$. In all cases at least three isolates of $C$. difficile from each animal were screened for in-vitro production of cytotoxin. In addition, in experiments with animals receiving both a toxigenic and non-toxigenic strain of $C$. difficile, a large number of $C$. difficile was sampled by taking a sweep of the colonies at a low dilution on an agar plate with a wire loop and inoculating the bacteria into CMC broth for cytotoxin production (Borriello and Honour, 1983).

\section{Animals and experimental groups}

Animals. Adult Syrian hamsters (Mesocricetus auratus) supplied from the National Institute for Medical Research were used in all the experiments. Each received $0.5 \mathrm{ml}$ of a solution containing clindamycin phosphate (Dalacin C; Upjohn, Crawley, West Sussex) $10 \mathrm{mg} / \mathrm{ml}$ i.p. and were housed individually in filter-lidded isolator cages (Larson et al., 1980). The cages, food, water bottles and bedding were autoclaved in sealed bags before use. Five days after receiving clindamycin the hamsters were divided into five main experimental groups:

Group 1-23 hamsters each received an oral dose of $0 \cdot 3 \mathrm{ml}$ of a suspension of non-toxigenic C. difficile, and the cages were resealed; 17 received strain $\mathrm{M}-1\left(c .3 \times 10^{7}\right.$ organisms $)$, three strain S-1 (c. $3 \times 10^{9}$ organisms), and three strain D-1 (c. $3 \times 10^{6}$ organisms). An additional 21 hamsters served as positive controls and received $0.3 \mathrm{ml}$ of $\mathrm{BHI}$ broth alone. After 5 days, the cages were opened briefly and fresh faecal pellets were collected into sterile glass 7-ml screw-capped bottles from all animals and cultured for $C$. difficile. At day seven, all but 10 of the animals received an oral dose of $0.3 \mathrm{ml}$ (c. $3 \times 10^{7}$ organisms) of a suspension of the toxigenic C. difficile strain B-1. Three of the group that had received strain $\mathrm{M}-1$, one that received strain $\mathrm{S}-1$, and one that received strain D-1 were given BHI broth alone on day seven, and five of the positive control group received strain B-1 on day 15 . Of the animals that received both strains $\mathrm{M}-1$ and $\mathrm{B}-1$ of $C$. difficile, five were killed on day 27 , one on day 31 and one on day 51 . Of the three animals receiving strain $\mathrm{M}-1$ alone, one was killed on day nine and two on day 51 . The two animals receiving either S-1 or D-1 alone were killed after 12 days.

One of the S-1-colonised hamsters was re-challenged with the toxigenic strain B-1 on day 55 and killed on day 75 . One of the D-1-colonised hamsters was re-challenged on day 55 . The four remaining S-1 or D-1 'mono-associated' animals had pellets taken at day 25 which were analysed for anti-toxic effects (see below). These animals were not observed further in view of the amount of handling and possible contamination at this time.

Group 2-Four hamsters received $0.3 \mathrm{ml}$ of an autoclaved suspension of the non-toxigenic strain M-1 (c. $3 \times 10^{7}$ killed organisms). This group then received strain B-1 and was treated in 
the same way as the B-1/M-1 hamsters in Group 1. A further two hamsters receiving strain B-1 alone served as positive controls.

Group 3-Three hamsters received $0.3 \mathrm{ml}$ of the non-toxigenic strain M-1 (c. $3 \times 10^{7}$ organisms). Two hamsters received BHI broth alone. All five hamsters were then given vancomycin (Vancocin $\mathrm{HCl}$; Eli Lilly, Basingstoke, England) in their drinking water at a concentration of $200 \mu \mathrm{g} / \mathrm{ml}$ over a period of 6 days. Fresh drinking water containing vancomycin was supplied after 3 days. The amount of water consumed by each hamster was recorded and the amount of vancomycin received was calculated (mean $12.8 \mathrm{mg}$; range $7-18 \mathrm{mg}$ ). Four days after discontinuing vancomycin, fresh pellets were collected from all animals and cultured for $C$. difficile. Eleven days later, all animals received $0.3 \mathrm{ml}$ of a suspension of strain B-1. The animals were observed daily.

Group 4-In this group of 12 animals, three received $0.3 \mathrm{ml}$ of a suspension of C. sporogenes (c. $3 \times 10^{8}$ cells); three received $C$. perfringens $\left(c .3 \times 10^{7}\right.$ cells); three received $C$. bifermentans $(c$. $3 \times 10^{6}$ cells); one received C. beijerincki $\left(\right.$ c. $3 \times 10^{5}$ cells $)$; and two received BHI broth alone. After 4 days, fresh pellets were collected from each of the animals and cultured for $C$. difficile and the other clostridia. Two days later all animals received $0.3 \mathrm{ml}$ of strain B-1. the animals were observed daily.

Group 5-Three animals received $0.3 \mathrm{ml}$ of strain M-1 and three BHI broth alone. After 5 days, fresh pellets were collected and cultured for $C$. difficile. Two days later, all animals received $0.3 \mathrm{ml}$ of a suspension of $C$. spiroforme (c. $3 \times 10^{2}$ organisms). The animals were observed daily. These experiments were done after all those with $C$. difficile had been completed.

At death or sacrifice, in all of the above experimental groups, the caecal contents were screened for cytotoxin and C. difficile (as well as C. spiroforme in Group 5) and the isolates were screened for in-vitro production of cytotoxin.

\section{Experiments to determine presence of antitoxic factors produced by strains $S-1$ and $D-1$}

1. Four hamsters were treated with clindamycin as described above. After 5 days, two pairs were challenged with $0 \cdot 3 \mathrm{ml}$ of strain S-1 and D-1 respectively. After 10 days the animals received $0.3 \mathrm{ml}$ of strain B-1. After 25 days, fresh pellets were collected from these animals and from a further two untreated animals housed in normal open cages. The pellets were emulsified in $\mathrm{BHI}$ broth to give ten-fold dilutions which were centrifuged at $4500 \mathrm{rpm}$ at $4{ }^{\circ} \mathrm{C}$ for $20 \mathrm{~min}$ and then filtered $(0.45 \mu \mathrm{m}$ pore size). BHI culture medium in which the toxigenic strain B-1 had grown for $72 \mathrm{~h}$ was centrifuged and filtered as above. This crude toxin preparation was diluted in BHI broth to give 5, 25, 50, 250, and 500-fold dilutions. A $0 \cdot 25-\mathrm{ml}$ portion of the filter-sterilised faecal pellet supernate was added to an equal volume of each of these dilutions. In addition, a parallel set of the crude toxin dilutions received an equal volume of $C$. sordelli antitoxin $(0.25 \mathrm{ml})$. All dilutions were left at room temperature for $1 \mathrm{~h}$ and then screened for cytotoxigenic activity in tissue culture as described.

2. A preparation of crude cytotoxin was prepared from strain B-1 as described above. This was divided into equal volumes of $20 \mathrm{ml}$. To one, $0.25 \mathrm{ml}$ of an actively growing BHI broth culture of strain M-1 was added. Both aliquots of crude cytotoxin preparation were then incubated anaerobically for 3 days at $37^{\circ} \mathrm{C}$ when $2-\mathrm{ml}$ vols were thereafter removed at $24 \mathrm{~h}$ intervals for determination of cytotoxin titres and, where relevant, viable counts of $C$. difficile.

\section{Mucosal association studies}

The three animals from experimental Group 1 that were killed at day 51 were used to assess the degree of mucosal colonisation of the caecum by strain M-1. The caeca were removed and opened, and the contents were removed by gentle washing in a BHI broth:physiological saline mix (1:1) (BHIS). A piece of caecum was removed and washed in BHIS by agitating the washing broth over the tissue in a sterile petri dish with a pasteur pipette. The tissue was transferred to another sterile petri dish and this washing procedure was repeated eight times. The washed tissue was weighed $(c .0 \cdot 1 \mathrm{~g})$, and an accurate ten-fold dilution was made in BHI broth. The tissue was thoroughly homogenised with a sterile glass tissue grinder and eight serial ten-fold dilutions of the homogenate prepared. Numbers of $C$. difficile present were determined by application of 10 
$\mu 1$ of each dilution in triplicate to the selective medium for $C$. difficile described above. The concentration of $C$. difficile in the eighth washing was similary determined. After incubation the mean count was determined and three of the colonies from each final wash and each homogenate were screened for their ability to produce cytotoxin in vitro.

Histological examination-Material was prepared as described by Price et al. (1979) and examined by Dr A. B. Price of the Department of Histopathology, Northwick Park Hospital.

\section{RESULTS}

\section{Group 1 study}

The design of this study was to determine first whether non-toxigenic strains of $C$. difficile (see Methods) would establish asymptomatically in hamsters, and second the extent to which animals colonised in this way would be protected from disease after exposure to a known toxigenic strain of $C$. difficile. The opportunity was also taken to look for evidence of translocation (invasion) across the gut wall by $C$. difficile, and on a selected number of animals to examine the histology of the caecum. All hamsters receiving only the toxigenic strain B-1 died within $48 \mathrm{~h}$ of exposure to this organism, whether challenged within 5 or 15 days of receiving clindamycin. In all cases cytotoxin was detected in the caecal contents and cytotoxigenic $C$. difficile were present. Of the three animals receiving only the non-toxigenic strain $\mathrm{M}-1$, one was killed on day 9 and two on day 51 ; all had only non-cytotoxigenic strains present and had no cytotoxin in the caecum. The two animals colonised with the non-toxigenic strains S-1 or D-1 alone had no detectable cytotoxin and only non-cytotoxigenic $C$. difficile was detected in their caecal contents when killed. Moreover, no caecal abnormalities were detected on histological examination.

Of the 14 animals receiving both strains $M-1$ and B-1, five were killed on day 27 , one on day 31 and one on day 51. Others died on days 10, 12, 13 (two deaths), 22, 29 and 48. The findings in the pellets and caeca of these animals are presented in the table. In addition to the normal investigations, samples of heart blood and liver from the animal killed on day 31 were screened for $C$. difficile. Cytotoxigenic strains were isolated from both sites. Histological analysis of the caecum showed very early signs of caecitis.

One hamster colonised with strain S-1 and one colonised with D-1 which were subsequently challenged with strain B-1 on day 7 had only non-cytotoxigenic strains detected in their pellets on days 14, 35, 40 and 55. After re-challenge with strain B-1 on day 55 , the hamster colonised with strain D-1 died 13 days later and had toxin and cytotoxigenic $C$. difficile in the caecum. The hamster colonised with strain S-1 was killed 20 days after re-challenge; no cytotoxin could be detected in the caecal contents, and only non-cytotoxigenic $C$. difficile could be detected. The histology was entirely normal and $C$. difficile was not found in the liver or heart blood. The other hamsters all survived for 25 days, at which time the experiment was terminated for these animals.

In total, 18 hamsters in Group 1 were colonised with a non-toxigenic strain of $C$. difficile before exposure to the toxigenic pathogenic strain. Of these, 13 survived for at least 25 days (see figure), on which day one of the animals was killed. All five animals that died before this day had detectable cytotoxin and cytotoxigenic $C$. difficile in their caeca. None of the five hamsters colonised with only non-toxigenic $C$. difficile died during the observation periods. 
TABLE

Findings in hamsters receiving both non-toxigenic C. difficile (strain M-1) and toxigenic C. difficile (strain B-1)

\begin{tabular}{|c|c|c|c|c|c|c|c|c|c|}
\hline \multirow{2}{*}{$\begin{array}{c}\text { Time of } \\
\text { death (days) } \\
\text { after challenge }\end{array}$} & \multirow{2}{*}{$\begin{array}{l}\text { Number of } \\
\text { survivors }\end{array}$} & \multirow{2}{*}{$\begin{array}{l}\text { Number } \\
\text { dead }\end{array}$} & \multirow{2}{*}{$\begin{array}{l}\text { Number } \\
\text { killed }\end{array}$} & \multicolumn{3}{|c|}{$\begin{array}{c}\text { Finding of } C \text {. difficile } \\
\text { in pellet (day after exposure) }\end{array}$} & \multicolumn{3}{|c|}{$\begin{array}{l}\text { Findings in caecal content at death } \\
\text { C. difficile }\end{array}$} \\
\hline & & & & cytotoxigenic & & non-cytotoxigenic & cytotoxigenic & non-cytotoxigenic & cytotoxin \\
\hline 0 & 14 & 0 & 0 & $\ldots$ & & $\ldots$ & $\ldots$ & $\ldots$ & $\ldots$ \\
\hline 10 & 13 & 1 & 0 & + & (7) & -- & + & - & + \\
\hline 12 & 12 & 1 & 0 & $\ldots$ & & $\ldots$ & + & - & + \\
\hline 13 & 10 & 2 & 0 & $\ldots$ & & $\ldots$ & + & - & + \\
\hline 22 & 9 & 1 & 0 & $\ldots$ & & $\ldots$ & + & - & + \\
\hline 27 & 8 & 0 & 1 & - & (12) & + & + & - & + \\
\hline 27 & 6 & 0 & 2 & - & (12) & + & - & + & + \\
\hline 27 & 5 & 0 & 1 & - & (12) & + & - & + & - \\
\hline 27 & 4 & 0 & 1 & + & (12) & + & + & - & - \\
\hline 29 & 3 & 1 & 0 & - & $\begin{array}{r}(7) \\
(24)\end{array}$ & $\begin{array}{l}+ \\
+\end{array}$ & + & - & + \\
\hline $31 *$ & 2 & 0 & 1 & $\begin{array}{l}+ \\
- \\
+\end{array}$ & $\begin{array}{r}(7) \\
(24)\end{array}$ & $\begin{array}{l}+ \\
+ \\
-\end{array}$ & + & - & + \\
\hline 48 & 1 & 1 & 0 & $\ldots$ & & $\ldots$ & + & - & + \\
\hline $51 \dagger$ & 0 & 0 & 1 & $\ldots$ & & $\ldots$ & - & + & - \\
\hline
\end{tabular}

is

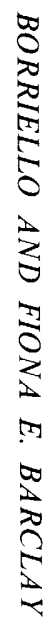

* Cytotoxigenic $C$. difficile also isolated from heart blood and liver; histology of caecum showed very early signs of disease. $\dagger$ Only non-cytotoxigenic $C$. difficile found adhering to the caecum.

... Not analysed; + present; - not detected. 


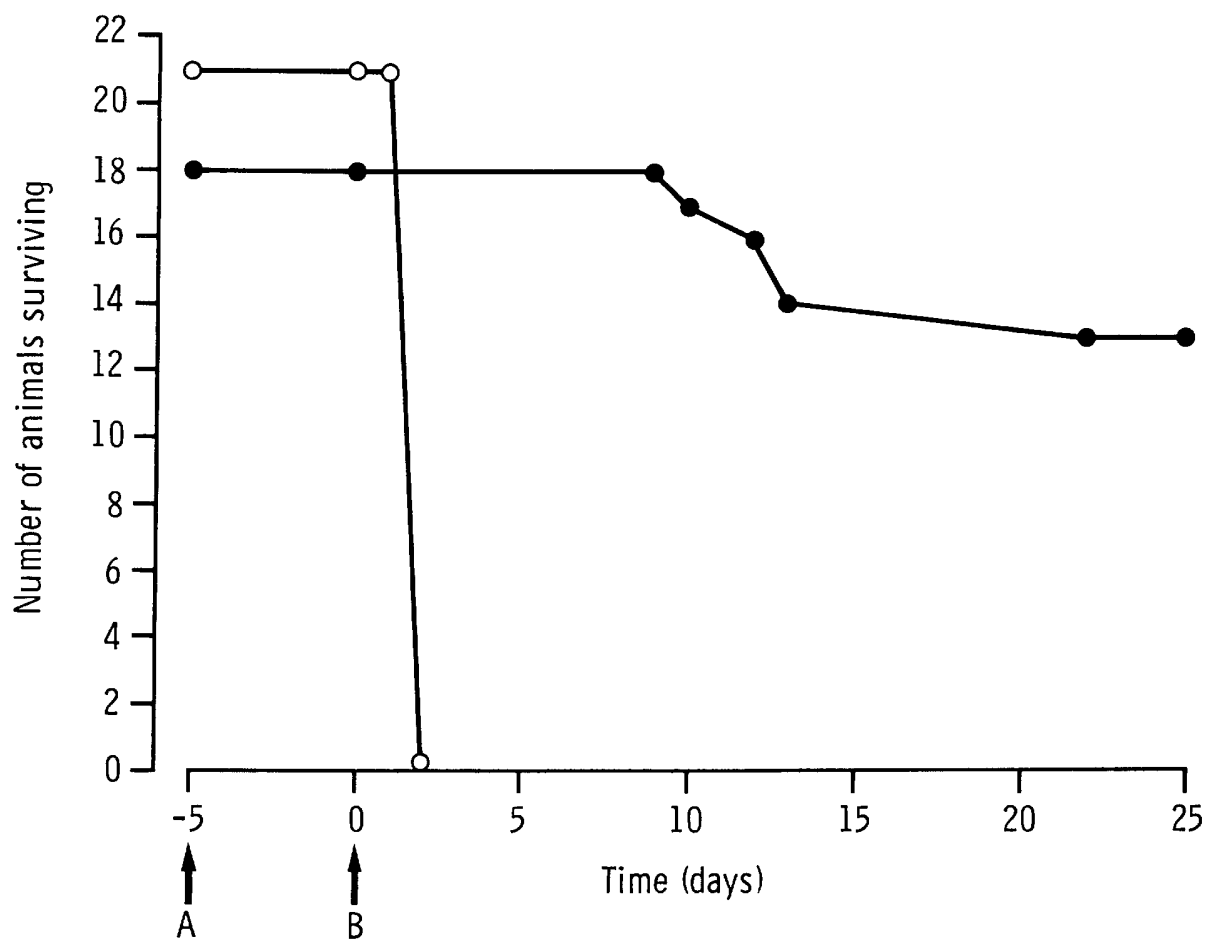

FiGURE - Survival of protected and non-protected hamsters. A-Clindamycin pre-treated hamsters received $\mathrm{BHI}$ broth $(\mathrm{O})$ or non-toxigenic $C$. difficile $(\bullet)$ orally. $\mathrm{B}-\mathrm{All}$ animals received toxigenic $C$. difficile strain B-1 orally at day 0 .

\section{Group 2 study}

With this group of animals, the Group-1 study was repeated but with a heat-killed suspension of the non-toxigenic strain M-1 in an attempt to determine whether protection depended upon colonisation with viable organisms.

Four animals received a heat-killed suspension of the protective M-1 strain and were shown to be free of $C$. difficile by analysis of faecal pellets 5 days later. Within $24 \mathrm{~h}$ of receiving the pathogenic strain all animals, including those receiving strain B-1 alone, were dead. In all cases the caecal contents were positive for cytotoxin and toxigenic $C$. difficile.

\section{Group 3 study}

For further confirmation that protection depended upon colonisation by the non-toxigenic strain, and also to show that the continued presence of these strains was necessary, a group of colonised animals was treated with vancomycin to remove the 'protective' strain before challenging them with a toxigenic strain.

The three animals receiving the non-toxigenic strain M-1 were shown to have been successfully colonised by analysis of their pellets 6 days later. All had non-cytotoxigenic strains present. The two control animals that did not receive strains M-1 were free 
of detectable $C$. difficile. After treatment with vancomycin, none of the animals had detectable $C$. difficile. Within 2 days of receiving the pathogenic strain B-1, all five animals were dead. All had cytotoxigenic $C$. difficile present in their caeca and three of the animals also had cytotoxin present. The two animals without detectable levels of cytotoxin in the caecal contents had both previously received strain $\mathrm{M}-1$ which had then been eradicated with vancomycin.

\section{Group 4 and Group 5 studies}

To investigate the specificity of the protection, animals (Group 4) were given various other clostridial species before exposure to toxigenic $C$. difficile. Others were first colonised with the protective non-toxigenic strains of $C$. difficile but then exposed to a different clostridial pathogen, $C$. spiroforme (Group 5). Of the other clostridia used in the Group-4 experiments, $C$. perfringens, $C$. bifermentans and $C$. beijerincki failed to colonise the hamsters. The animals did become colonised with $C$. sporogenes; all three of these animals died within $24 \mathrm{~h}$ of subsequently receiving the pathogenic strain of $C$. difficile. In all three cases, $C$. sporogenes, cytotoxigenic $C$. difficile, and cytotoxin were present in the caecal contents. The two control animals that were not exposed to other clostridia before receiving the pathogenic strain of $C$. difficile died within $24 \mathrm{~h}$ and cytotoxigenic $C$. difficile and cytotoxin were present in the caecal contents.

All six animals in the Group-5 experiment died within $48 \mathrm{~h}$ of receiving cytotoxigenic $C$. spiroforme, irrespective of prior colonisation with the non-toxigenic M-1 strain of $C$. difficile. In all cases, cytotoxigenic $C$. spiroforme was recovered from the caecum and a cytopathic toxin that could be completely neutralised by the cross-reacting anti- $C$. perfringens type $\mathrm{E}$ iota toxin was present.

\section{Production or induction of antitoxic factors}

It was possible that the protection noted in the animals in experimental Group 1 might have been due to the induction of antitoxin in the gastrointestinal tract of the host, or that the non-toxigenic strains were themselves able to degrade $C$. difficile cytotoxin. However, although the culture filtrate of the toxigenic B-1 strain of $C$. difficile induced a cytopathic effect at a dilution of 1 in 500, the addition of cell-free filtrates of a ten-fold dilution of pellets from hamsters colonised with the non-toxigenic strains S-1 or D-1 of $C$. difficile or from normal hamsters did not alter the observed cytotoxin titres. Moreover, incubation of a crude cytotoxin preparation with the non-toxigenic M-1 strain of $C$. difficile had no observed effect on the cytotoxin titre which remained at 4096 over the 3-day period, despite a ten-fold increase in the numbers of $C$. difficile (strain $\mathrm{M}-1$ ) during this period.

\section{Mucosal association}

An important factor in the pathogenicity of many gut pathogens is their ability to adhere to the mucosal lining of the gastrointestinal tract. It was thought possible that protection from disease afforded by the non-toxigenic strain could be due to competition for various niches, including those at the mucosal surface. To determine whether non-toxigenic strains had the ability to adhere to the mucosal lining of the 
caecum, this was investigated in two animals that had been colonised by the non-toxigenic strain M-1 alone, and in one animal that had been colonised with strain M-1 and successfully protected against disease after exposure to the toxigenic strain of C. difficile.

All three animals that were killed after 51 days in the Group-1 study had only non-cytotoxigenic $C$. difficile found intimately associated with caecal mucosa, as well as only non-cytotoxigenic strains in the caecal contents (see the table). The numbers of $C$. difficile found in the eighth washing of caecal material were $6 \times 10^{2}, 1 \times 10^{2}$ and $4 \times 10^{3} / \mathrm{ml}$, and counts of those found remaining associated with the caecal mucosa were $1 \times 10^{5}, 6 \times 10^{3}$ and $3 \times 10^{5} / \mathrm{g}$ of tissue respectively.

\section{DISCUSSION}

We have previously shown with a small group of animals that prior colonisation of clindamycin-treated hamsters with a non-toxigenic strain of $C$. difficile affords protection against subsequent challenge with a toxigenic pathogenic strain (Borriello et al., 1982 and 1983). These findings were independently confirmed by Wilson and Sheagren (1983) who demonstrated that 26 of 28 hamsters pre-colonised with a non-cytotoxigenic strain survived a subsequent challenge with a cytotoxigenic strain whereas only 6 of 28 survived colonisation with the cytotoxigenic strain alone and only 9 of 28 survived simultaneous colonisation with both strains. Unfortunately, the period of survival for the 'protected' hamsters was not stated. Both of the above studies were limited and there was no information on the specificity of protection or possible mechanisms of action.

The results of the present study add further confirmation to the observation that non-toxigenic strains of $C$. difficile, which were shown also to be non-pathogenic, can protect against colonisation with a toxigenic pathogenic strain. Of the 18 protected animals in our studies, 13 survived for at least 25 days and this protection was afforded by different non-toxigenic strains. However, it is clear that full protection is not achieved. Extended observation of the challenged animals showed that death occurred in most cases and that cytotoxigenic $C$. difficile and cytotoxin could be detected in their caeca. When faecal pellets from some of these animals were analysed sequentially, it could be seen that the situation started to change from one in which only non-cytotoxigenic $C$. difficile could be isolated to one in which only cytotoxigenic or both types could be found. In all cases at death, other than killing for examination, free cytotoxin was present in the caecum and cytotoxigenic $C$. difficile could be isolated. It is probable that with time in an isolated environment where the animal is continually re-exposed to the toxigenic strain of $C$. difficile as a result of excretion and faecal soiling of its environment, cleaning and coprophagy, this strain eventually manages to establish itself in the gut. There is some evidence for this in that one of two protected animals that were deliberately re-challenged with a heavy dose of toxigenic $C$. difficile 55 days after colonisation with the non-toxigenic strain died within 13 days and had cytotoxigenic $C$. difficile and cytotoxin present in the caecum. However, the other animal was still able to prevent colonisation by the toxigenic strain. The results imply that the ability to produce toxin may confer some ecological advantage on these strains. The other possible explanation for the emergence of a cytotoxigenic strain with time is that cytotoxin production in the non-toxigenic strain is somehow switched on in 
vivo. This seems to be unlikely as cytotoxigenic isolates of $C$. difficile did not emerge in detectable levels in the faecal pellets or caeca of animals colonised by only the non-toxigenic strains, even when kept in this colonised state for up to 51 days. It is also of interest that in one of the animals only very early signs of disease were apparent at histological examination of the killed animal 7 days after detecting cytotoxigenic strains in the faecal pellet. Despite only early microscopic signs of disease, the toxigenic strain had translocated across the gut wall and was recovered from heart blood and liver. Evidence of translocation was not noted in the one non-toxigenic-colonised animal investigated in this way. These early signs of disease were probably a feature of the presence of the toxigenic strain as they were not noted in animals colonised with a non-toxigenic strain for a longer period.

The protection observed required the presence of viable non-toxigenic, non-pathogenic $C$. difficile. No protection occurred if the animals were given a heat-killed suspension of the organism. In addition, if the colonising protective non-pathogenic strain of $C$. difficile was reduced to undetectable levels by treatment with vancomycin before challenge with the pathogenic strain, then again all protection was lost. This implies that under these experimental conditions there was no memory for protection and that protection depends upon the presence of viable non-pathogenic $C$. difficile. These findings imply that some sort of immune protective response in not the major factor involved. Moreover, colonisation of the hamster with non-toxigenic $C$. difficile apparently failed to induce the production of anti-cytotoxin in the faecal pellets. Further, as the non-toxigenic strain tested failed to degrade cytotoxin, in-vivo degradation of the toxin as a means of protection is an unlikely explanation.

The protection noted in these experiments is specific in that other species of clostridia would not protect the animals against disease. This was true even of $C$. sporogenes which did establish in the gut. It was unfortunate that $C$. beijerincki failed to colonise because this organism has been shown to exhibit almost totally specific bactericidal activity against $C$. difficile in vivo (Barclay and Borriello, 1980). Likewise, prior colonisation of the animals with a non-pathogenic strain of $C$. difficile failed to protect from disease and death when they were exposed to a different clostridial pathogen, $C$. spiroforme.

The specificity of protection and the need for the presence of viable bacteria imply that the mechanism of protection may be one of direct competition either for necessary nutrients or for specific ecological niches such as those at mucosal receptor sites. Mucosal association is an important pathogenic mechanism for many bacteria. We have shown previously that cytotoxigenic $C$. difficile can be found intimately associated with the rectal mucosa of man (Borriello, 1979) as well as the mucosal lining of the caecum in hamsters (Borriello, 1984). In this study we have shown that a non-pathogenic strain will also associate with the mucosal lining of the caecum and that this colonisation can be durable. There is, therefore, the possibility that protection occurs because of competition for the specific mucosal receptor sites required for establishment of the pathogenic strain.

Although it is apparent that the presence of a non-pathogenic strain of $C$. difficile in the gut will only give some protection against colonisation with a pathogenic strain it is possible that full protection would have occurred if the animals had also been exposed to the normal environment. In this situation, the initial exclusion of the pathogenic strain may have been sufficient to protect the animals while they were re-establishing a 
normal gut flora which would then be capable of fully protecting the animals. The extent to which this sort of approach may be therapeutically useful in treatment or management of antibiotic-associated diarrhoea is difficult to assess. It is doubtful whether a non-pathogenic strain would displace an established pathogenic strain of $C$. difficile. However, it is possible that a patient with a history of relapse might be protected by colonisation with a non-pathogenic strain against re-colonisation by a pathogenic variant. It is important in this context that Borriello and Honour (1983) have isolated both toxigenic and non-toxigenic types of $C$. difficile simultaneously from individual specimens of human faeces in which cytotoxin could be detected, despite the non-cytotoxigenic strains being the numerically dominant type. One of the subjects in this study had pseudomembranous colitis. Whether these findings are indicative of the lack of effective antagonism between these bacteria is difficult to assess as the sequence of colonisation was unknown. However, as re-infection or relapse can occur after antimicrobial therapy directed against $C$. difficile in as many as $20 \%$ of cases (Bartlett $e t$ al., 1980; Fekety et al., 1981), bacteriotherapy with non-pathogenic strains of $C$. difficile may warrant further consideration.

F.E.B. wishes to acknowledge that some of this work was performed as part of the requirement for FIMLS by thesis. S. P. B. was supported by Upjohn International. Histological examination was performed by Dr A. B. Price.

\section{REFERENCES}

Banno Y, Kobayashi T, Watanabe K, Ueno K, Nozawa Y 1981 Two toxins (D-1 and D-2) of Clostridium difficile causing antibiotic-associated colitis: purification and some characterization. Biochemistry International 2:629-635.

Barclay F E, Borriello S P 1982 In vitro inhibition of $C$. difficile. European Journal of Chemotherapy and Antibiotics 2:155-156.

Barclay F E, Borriello S P 1984 Clostridium difficile and colonization resistance. In: Borriello S P (ed) Antibiotic-associated diarrhoea and colitis. Martinus Nijhoff Publishers. The Hague, p79.

Bartlett J G, Chang T-W, Gurwith M, Gorbach S L, Onderdonk A B 1978 a Antibiotic-associated pseudomembranous colitis due to toxin-producing clostridia. New England Journal of Medicine 298:531-534.

Bartlett J G, Chang T-W, Onderdonk A B $1978 b$ Comparison of five regimens for treatment of experimental clindamycin-associated colitis. Journal of Infectious Diseases 138:81-86.

Bartlett J G, Onderdonk A B, Cisneros R L 1977 Clindamycin-associated colitis in hamsters: protection with vancomycin. Gastroenterology 73:772-776.

Bartlett J G, Tedesco F J, Shull S, Lowe B, Chang T-W 1980 Symptomatic relapse after oral vancomycin therapy of antibiotic-associated pseudomembranous colitis. Gastroenterology 78:431-434.

Borriello S P 1978 An evaluated micromethod for the detection of Clostridium difficile enterotoxin. Microbios Letters 7:25-28.

Borriello S P 1979 Clostridium difficile and its toxin in the gastrointestinal tract in health and disease. Research and Clinical Forum 1:33-35.

Borriello S P 1984 Clostridium difficile and gut disease. In: Goodwin C S (ed) Microbes and infections of the gut. Blackwell Scientific Publications, Oxford, p327.

Borriello S P, Barclay F E 1984 Clostridium difficile infection-protection by prior colonization with non-pathogenic strains. In: Hill $\mathbf{M} \mathbf{J}$ (ed) Models of anaerobic infection. Martinus Nijhoff Publishers, The Hague, p 239.

Borriello S P, Carman R J 1983 Association of iota-like toxin and Clostridium spiroforme with both spontaneous and antibiotic-associated diarrhea and colitis in rabbits. Journal of Clinical Microbiology 17:414-418. 
Borriello S P, Honour P 1981 Simplified procedure for the routine isolation of Clostridium difficile from faeces. Journal of Clinical Pathology 34:1124-1127.

Borreillo S P, Honour P 1983 Concomitance of cytotoxigenic and non-cytotoxigenic Clostridium difficile in stool specimens. Journal of Clinical Microbiology 18:1006-1007.

Borriello S P, Honour P, Turner T, Barclay F 1983 Household pets as potential reservoir for Clostridium difficile infection. Journal of Clinical Pathology 36:84-87.

Borriello S P, Hudson M J, Hill M J 1978 Investigation of the gastrointestinal bacterial flora. Clinics in Gastroenterology 7:329-349.

Borriello S P, Larson H E, Honour P, Barclay F E 1982 Antibiotic-associated diarrhoea and colitis. In: Clinical Research Centre Report. Medical Research Council, London, pp 96-98.

Bowden T A, Mansberger A R, Lykins L E 1981 Pseudomembranous enterocolitis: mechanism of restoring floral homeostasis. American Surgeon 47:178-183.

Browne R A, Fekety R, Silva J, Boyd D I, Work C O, Abrams G D 1977 The protective effect of vancomycin on clindamycin-induced colitis in hamsters. John Hopkins Medical Journal 141:183-192.

Chang T-W, Bartlett J G, Gorbach S L, Onderdonk A B 1978 Clindamycin-induced enterocolitis in hamsters as a model of pseudomembranous colitis in patients. Infection and Immunity 20:526-529.

Crowther J S 1971 Transport and storage of feces for bacteriological examination. Journal of Applied Bacteriology 34:477-483.

Fekety R, Silva J, Armstrong J, Allo M, Browne R, Ebright J, Lusk R, Rifkin G, Toshniwal R 1981 Treatment of antibiotic-associated enterocolitis with vancomycin. Reviews of Infectious Diseases 3 (suppl.):S273-S281.

George W L, Sutter V L, Citron D, Finegold S M 1979 Selective and differential medium for isolation of Clostridium difficile. Journal of Clinical Microbiology 9:214-219.

Holdeman L V, Cato E P, Moore W E C (eds) 1977 Anaerobe laboratory manual, 4th edn. Virginia Polytechnic Institute and State University, Blacksburg, VA.

Koransky J R, Allen S D, Dowell V R 1978 Use of ethanol for selective isolation of sporeforming micro-organisms. Applied and Environmental Microbiology 35:762-765.

Larson H E, Price A B, Borriello S P 1980 Epidemiology of experimental enterocecitis due to Clostridium difficile. Journal of Infectious Diseases 142:408-413.

Lyerly D M, Sullivan N M D, Wilkins T D 1983 Enzyme-linked immunosorbant assay for Clostridium difficile toxin A. Journal of Clinical Microbiology 17:72-78.

Malamou-Ladas H, Tabaqchali S 1982 Inhibition of Clostridium difficile by faecal streptococci. Journal of Medical Microbiology 15:569-574.

Price A B, Larson H E, Crow J. 1979 Morphology of experimental antibiotic-associated enterocolitis in the hamster: a model for human pseudomembranous colitis and antibioticassociated diarrhoea. Gut 20:467-475.

Raibaud P, Ducluzeau R, Dubos F, Hudault S, Bewa H, Muller M C 1980 Implantation of bacteria from the digestive tract of man and various animals into gnotobiotic mice. Americal Journal of Clinical Nutrition 33:2440-2447.

Rolfe R D, Helebian S, Finegold S M 1981 Bacterial interference between Clostridium difficile and normal faecal flora. Journal of Infectious Diseases 143:470-475.

Schwan A, Sjolin S, Trottestam U, Aronsson B 1984 Relapsing Clostridium difficile enterocolitis cured by rectal infusion of normal faeces. Scandinavian Journal of Infectious Diseases 16:211-215.

Willey S H, Bartlett J G 1979 Cultures for Clostridium difficile in stools containing a cytotoxin neutralized by Clostridium sordelli antitoxin. Journal of Clinical Microbiology 10:880-884.

Wilson K H, Kennedy M J, Fekety F R 1982 Use of sodium taurocholate to enhance spore recovery on a medium selective for Clostridium difficile. Journal of Clinical Microbiology 15: 443-446.

Wilson K H, Sheagren J N 1983 Antagonism of toxigenic Clostridium difficile by non-toxigenic C. difficile. Journal of Infectious Diseases 147:733-736.

Wilson K H, Silva J, Fekety F R 1981 Suppression of Clostridium difficile by normal hamster cecal flora and prevention of antibiotic-associated cecitis. Infection and Immunity 34:626-628. 